\title{
Justiça reparativa e sanções na Igreja: uma visão jurídica ${ }^{1}$
}

\author{
Restorative justice and sanctions in the Church: a juridical owerview
}

Michele Riondino $^{2}$

Resumo: A intervenção está dividida em três pontos. Começarei apresentando de forma resumida as chaves mais importantes do ideal de justiça penal reparativa e os conceitos técnicos de maior alcance que a doutrina foi respectivamente elaborando. Depois, vou indicar algumas das dificuldades que se apresentam na interpretação do direito penal canônico vigente e sobre quais delas a orientação da justiça reparativa poderia servir de ajuda. Por fim, apontarei aquelas que, segundo meu entendimento, caberiam considerar como condições indispensáveis para que esse enriquecimento se possa verificar com proveito.
Abstract: The intervention is divided into three points. I will begin by briefly presenting the most important keys to the ideal of reparative criminal justice and the more far-reaching technical concepts that doctrine has been elaborating. Then I will point out some of the difficulties that arise in the interpretation of canonical penal law in force and on which the orientation of reparatory justice could serve as an aid. Lastly, I will point out those that, in my opinion, should be considered as indispensable conditions for this enrichment to be profitable.

1 Sétima conferência proferida no II ${ }^{\circ}$ Simpósio Canônico "Questões seletas de Direito Matrimonial e Penal Canônico", promovido pelo Instituto Superior de Direito Canônico Santa Catarina em 8-9 de maio de 2018.

2 Michele Riondino (1978) é professor titular de Direito Canônico na Faculdade de Direito Thomas More da Australian Catholic University, onde também leciona Direito dos Menores e professor de Direito Penal Canônico na Pontificia Università Lateranense. É autor de Giustizia riparativa e mediazione nel diritto penale canonico (2011, segunda edição 2012 ), Famiglia e Minori. Temi giuridici e canonici (2011) e de numerosos artigos e ensaios publicados em periódicos jurídicos internacionais. Com Manuel J. Arroba Conde publicou Introduzione al diritto canonico (2015, segunda edição 2017, terça edição 2019). Apresentou conferências na Europa, América, África, Ásia e Austrália. 
Palavras-chave: Justiça reparativa. Direito penal canônico. Hermenêutica jurídica.
Keywords: Reparative justice. Canonical penal law. Juridical hermeneutics.

\section{Introdução}

Agradeço a oportunidade de partilhar com vocês inquietudes e abordagens no estudo do direito penal da Igreja. Os ideais que propõe a penalística extra canônica identificada no conceito de justiça reparativa os conheci como estudante em Milão, onde o professor Stella ensinava direito penal, sendo um dos autores italianos que mais difundiu essa teoria. Depois tive a oportunidade de aprofundá-la em um curso de criminologia, em que fui chamado pelo professor Eusebi para ser o seu assistente, cujos esforços, tanto no estudo teórico da justiça reparativa, como em sua implementação efetiva nos tribunais, são bem conhecidos entre os penalistas.

Nos meus primeiros anos de estudante de direito canônico já fiz um trabalho sobre a possível relação entre a justiça reparativa e o sistema penal da Igreja, encontrando nele um campo de interesse para futuros estudos, a ponto de ter decidido dedicar minha tese de doutorado ao tema, onde tratei conjuntamente a justiça reparativa e as técnicas de mediação. Agora vou expor sinteticamente as razões pelas quais creio que a teoria da justiça reparativa pode ser enriquecedora, particularmente neste momento eclesial que atravessamos. Seu aproveitamento poderia favorecer a revisão do direito penal canônico, ainda em curso, para que não fique colocando remendos de aparência mais dura, mas que desemboque em um testemunho útil de cultura jurídica corajosa e profética, em relação aos valores que estão em jogo.

Vou dividir minha intervenção em três pontos. Em atenção àqueles que podem não conhecê-lo, começarei apresentando de forma resumida as chaves mais importantes do ideal de justiça penal reparativa e os conceitos técnicos de maior alcance que a doutrina foi respectivamente elaborando. Depois, vou indicar algumas das dificuldades que se apresentam na interpretação do direito penal canônico vigente e sobre quais delas a orientação da justiça reparativa poderia servir de ajuda. Por fim, apontarei aquelas que, segundo meu enten- 
dimento, caberiam considerar como condições indispensáveis para que esse enriquecimento se possa verificar com proveito.

\section{As chaves principais da justiça penal reparativa}

Para não me estender demais em aspectos teóricos, creio que o melhor modo de apresentar a justiça penal reparativa é confrontá-la com os dois modelos de direito penal frente aos quais pretende representar um progresso, seja no que se refere à função da pena, seja no que diz respeito à suas características e conteúdos.

É preciso esclarecer, de início, que a expressão "justiça reparativa" indica um paradigma com o qual se pretende sublinhar, frente ao direito penal tradicional, a função de responsabilizar e conciliar que cabe a pena. Por responsabilizar, entendem-se medidas que suscitem no autor do delito um compromisso livre e convencido para respeitar, no futuro, os valores protegidos pelo ordenamento jurídico, e que não deixem qualquer dúvida sobre o fato de que possa resultar inconveniente violar a lei. Por conciliação se entende medidas que evitem colocar a vítima à margem da reação do ordenamento jurídico contra o delito.

Responsabilizar e reconciliar são objetivos e conteúdos que não consentem reduzir o dilema sobre o significado das sanções às duas correntes que costumam marcar os debates de política e sociologia criminal e que refletem as duas orientações que desde há muito tempo ocupam a cena dos estudos do direito penal. Refiro-me ao significado expiatório e educativo da pena, com as respectivas teorias retributiva e reeducativa. As dificuldades que encerra cada modelo não se resolvem apostando em um ou outro, mesmo parecendo que o exijam as urgências sociais de cada momento. $\mathrm{O}$ modelo da justiça reparativa pretende abandonar o beco sem saída que conduz a lógica que compartilham essas duas orientações, apesar de suas diferenças, isto é, a lógica da reciprocidade diante do mal. Trata-se de substituir essa lógica negativa, com a lógica positiva da alteridade em relação ao mal. Vejamos estas diferenças com maior detalhe.

Segundo a teoria retributiva a resposta do ordenamento jurídico diante do delito deve guiar-se por uma reciprocidade do tipo analógi- 
ca, isto é, com intervenções que propiciem ao autor consequências negativas simétricas à negatividade que implica seu delito, único modo de impedir a prevaricação que o próprio delito supõe. Assim, o exigiria uma justiça entendida como "dar a cada um o que é seu", pensando que esse "o que é seu" possa se estabelecer com objetividade. A finalidade absoluta seria restabelecer a ordem justa, castigando o delito, sem se colocar outros problemas como, por exemplo, o dos resultados reais aos quais de fato essa estratégia conduz em relação à diminuição da criminalidade. Somam-se a essa lacuna outras duas: a impossibilidade de estabelecer correspondências entre cada delito e seu respectivo castigo; e, sobretudo, a impossibilidade de um juízo racional e moral sobre as características concretas de cada sanção penal.

$\mathrm{Na}$ teoria reeducativa a resposta do ordenamento ao delito se configura desde uma reciprocidade de tipo proporcional, isto é, com intervenções que levem em consideração a periculosidade do delinquente e a utilidade social, obrigando, por um lado, a considerar a personalidade do autor do delito e a voluntariedade real de sua ação, e por outro, a eficácia corretiva e preventiva das sanções. Além de algumas duvidosas conclusões sobre a capacidade de cometer delitos, fruto de premissas deterministas, e do esquecimento das vítimas, um risco importante desta abordagem é sua excessiva dependência da reprovação social, tanto em despenalizar condutas como em endurecer as penas.

Não vou me deter na evolução corretiva de cada modelo. É suficiente dizer que a aceitação das finalidades preventiva e educativa tem acompanhado a negação da analogia (desde Cesare Becaria), e a afirmação maior do livre arbítrio. Tampouco creio útil entrar nas modernas abordagens neo-retributivas (que vê a necessidade social de reação ao delito como justificação das penas) ou neo-utilitaristas (onde a justificação se baseia em conseguir modificar a conduta do réu, distinguindo entre prevenção geral e especial). Ainda que neles ganhe força a ideia de que a verdadeira prevenção provém da credibilidade intrínseca do ordenamento penal, a reestruturação das penas mantêm em uma lógica de reciprocidade negativa.

A teoria da justiça reparativa parte de uma opção global de fundo que a separa dos demais modelos. Opta-se por desenhar a intervenção penal a partir de uma lógica positiva de alteridade em relação ao 
mal que consiste em perseguir o bem integral de todos os implicados no delito: a sociedade em seu conjunto, o autor e a vítima. Considerase que reagir diante do mal com projetos que representem a antítese do mal seja a única via capaz de responsabilizar e de restaurar relações humanas autênticas. A orientação teórica se reforça com dados da experiência, como são os escassos resultados da justiça penal tradicional, tanto no que se refere à diminuição do crime quanto na utilidade das penas para satisfazer as exigências das vítimas.

Estes pressupostos sugerem centrar-se na capacidade do ordenamento jurídico de alavancar os meios necessários para que, mesmo antes da intervenção penal, resulte difícil cometer delitos e, para que, caso tenham sido cometidos, seja possível reparar as suas consequências sem se limitar a impor castigos que não resultem em responsabilizar e nem em reconciliar. A pena seria, pois, um instrumento para a aceitação livre das normas e para a descoberta de seu valor positivo. Por isso, deveriam ser estruturadas como um fazer e não como sofrimento, exceto aquele que deriva do esforço e do compromisso em revisar profundamente o próprio estilo de conduta. Mesmo comportando um fardo, as penas têm que assumir, antes de tudo, essa orientação positiva para o autor do delito.

Em relação à reconciliação com a vítima, esta teoria insiste em que as penas devem ser coerentes com os fatos cometidos, não no sentido de reproduzir sua negatividade, mas sim de expressar em seu conteúdo os valores violados. Essa força expressiva exige que a sanção consista em práticas reparativas, sem colocar toda ênfase na capacidade psíquica do réu ou em sua correção, mas permitindo uma participação da vítima que impeça ver a sanção como vingança ou mera extorsão pelo delito. Insiste-se muito que não pertence à pena em si, mas ao juízo penal, a tarefa de expressar o juízo social sobre a gravidade do delito, considerando os aspectos subjetivos que implica a relação com a vítima. Nesse contexto, a possibilidade de perdão não se concebe como uma alternativa para apontar o que está errado, mas para considerar o autor do delito como inimigo.

Os conceitos principais que traduzem esta orientação são, antes de tudo, o mesmo conceito de pena, que não se entende como privação de um bem, mas como projeto de bem personalizado, pois não é sufi- 
ciente seu objetivo genérico de ser contrapeso ao delito. Um segundo conceito é o da prevenção, expressada como prevenção primária, isto é, como compromisso cultural, e não somente penal, do ordenamento pelo respeito livre e crível dos valores que protege, com "tutela antecipada dos bens", com atenção às situações de risco que facilitam o cometimento de delitos e aos perfis de corresponsabilidade que poderia ter. Outros conceitos derivam da implicação obrigatória da vítima que, dentre outras coisas (que pertencem aos aspectos processuais), exige comunicação adequada dos delitos, impedir que proporcionem vantagens e assumir cargas significativas que, de fato, motivem o autor do delito a se responsabilizar por suas consequências, evitando presumir facilmente uma incapacidade para delinquir e reconhecendo a sua capacidade de submeter à revisão o próprio estilo de vida e de aderir no futuro às normas.

\section{Os possíveis problemas interpretativos do direito penal vigente}

Passo agora a apresentar alguns problemas interpretativos que afetam o direito penal canônico vigente e a partir dos quais considero enriquecedor recorrer à teoria da justiça reparativa. Também sobre este ponto, para evitar divagações complexas, me pareceu bem concentrar as dificuldades mais significativas em torno de cincos questões, três das quais relacionadas com a finalidade das penas, uma com sua constituição e outra com seus conteúdos.

A primeira questão é a dificuldade que envolve as fórmulas legais quanto a possibilidade de dispor uma finalidade integral às penas. Para não ir muito longe, em um recente congresso organizado pela faculdade de Comillas (Espanha), por ocasião dos trinta anos do Código, esta dificuldade foi indicada pelo Mons. Coccopalmerio como uma das razões que justificam a revisão do Livro VI, sustentando que as normas parecem distinguir a finalidade medicinal de corrigir o réu da finalidade de reparar o escândalo, atribuindo a cada tipologia uma ou a outra finalidade (às censuras, no primeiro caso, às penas expiatórias, no segundo). $\mathrm{O}$ cardeal advertia que não se podem estabelecer limites tão nítidos, insistindo que toda a pena tende à conversão do réu e, por- 
tanto, mesmo que faça parte do grupo das penas expiatórias, tem sempre uma finalidade medicinal.

Com isso passo a destacar aquela que, segundo meu parecer, pode resultar uma segunda questão problemática na hora de interpretar e aplicar as normas. Atrevo-me a formulá-la como uma espécie de "medicação excessiva" ou, melhor, como o recurso excessivo à natureza "medicinal" e pastoral do direito penal. Não se trata de negar essas conotações tão peculiares ao ordenamento canônico, mas de recordar que o acento que merece a recuperação do autor do delito não pode acarretar a marginalização de outros aspectos indispensáveis. Para um público de canonistas é desnecessário demonstrar a falácia implicada no recurso ao presumido dilema entre o jurídico-técnico e o pastoral. Nem tampouco é preciso insistir na união inseparável entre a centralidade de cada pessoa e as exigências irrenunciáveis da comunidade, que corresponde ao direito tutelar, sem que caibam fáceis contraposições. Nesse sentido, reduzir o pastoral ao medicinal, assim como limitar o medicinal a considerações de corte somente individual, entorpece a reta interpretação da finalidade integral das sanções.

O problema da reta interpretação da finalidade integral da pena é agravado pelas condições legais para impô-las e remiti-las. As medicinais, ao cessarem com o arrependimento do réu (conhecido como abandono da contumácia), correm o risco de marginalizar o bem da comunidade, pois sua remissão (em caso de emenda do autor do delito) é um ato de justiça e não de graça. Pelo contrário, as penas expiatórias, que poderiam ser perpétuas pela necessidade de se reparar o escândalo, podem continuar seus efeitos mesmo para quem tenha demonstrado um arrependimento sincero e eficaz. A incidência do arrependimento se obscurece ainda mais nos casos de excomunhão e interdito latae sententiae, por terem ambas as censuras (mesmo antes de terem sido declaradas) o efeito de excluir da reconciliação sacramental, com uma remissão de foro interno que pode criar confusões e deixar muito debilitada a avaliação da reparação dos danos.

A essa difícil conjunção entre as finalidades pessoais e comunitárias das penas se soma, como problema ulterior, e de maior envergadura, um tema que vai além das normas, ainda que tenha reflexos nelas, especialmente na norma geral com a qual se fecha o Livro VI. Po- 
demos expressar essa dificuldade mencionando o princípio de moderação que rege o sistema penal da Igreja desde sempre, e pelo qual a pena, no que se refere à sua aplicação, pode e deve se considerar a $e x$ trema ratio. O problema é se também se deve raciocinar em termos de moderação quando se trata da constituição das penas, isto é, da tutela penal por lei ou preceito de alguns valores essenciais. Nesse contexto, que a pena seja a extrema ratio não significa deixar de prevê-la, mas sim comprometer-se em assegurar, também por outras vias, sua capacidade preventiva.

Ao revisar o Código, no contexto do pós-concílio, talvez por reação ao casuísmo anterior, favoreceu-se a extensão do princípio de moderação para além do terreno próprio da aplicação das sanções, alcançando a previsão própria dos delitos, provocando sua diminuição significativa (não isenta de dificuldades), favorecendo, em alguns casos, certa passividade ou, em outros, permitindo intervenções tardias e suspeitas, amparadas no último cânon, com o risco de se recorrer à pena como mero instrumento de governo e sem as garantias que comporta o princípio de legalidade, desde que entendido com equilíbrio e sem excessos formalistas. A norma final não existe no Código oriental, porém o problema se pode apresentar em termos semelhantes, ao se fazer coincidir a obrigatória advertência prévia à sanção com o preceito com o qual se pode constituir um delito em um caso singular.

Não posso me deter nele, contudo, não quero deixar de indicar as ambiguidades às quais pode conduzir a diminuição dos delitos previstos, o que nem sempre obedece a adaptação da disciplina no sentido de não penalizar, mas, sim, a atribuição de excessiva relevância ao âmbito de jurisdição. Assim, referente à certas matérias (como as que afetam a moral social), considera-se suficiente a tutela penal por parte do ordenamento do Estado, talvez por carecer de meios próprios. Outras vezes se vincula o alcance canônico do delito ao estado de vida do autor, considerando o estado clerical como objeto de uma jurisdição eclesial mais eficaz, porém com o resultado absurdo de catalogar alguns delitos como violação de obrigações especiais, no lugar de entendê-los como delitos contra a dignidade humana. Além disso, ainda quando se trata de delitos tutelados no ordenamento canônico, exorta- 
se a discernir se pode ser suficiente a intervenção penal do Estado, com o risco de pecar tanto por defeito como por excesso.

Esta dificuldade de ater-se à possível sanção imposta na jurisdição do Estado nos introduz na quinta e última problemática, referente ao conteúdo da pena canônica. Costuma-se dar por certo que toda pena consiste na privação de um bem e, portanto, a finalidade pastoral consistiria em deixar de lado as questões técnicas e em ser flexíveis no momento de impor sanções, optando pelas menos duras. Segundo a tradição canônica, ao revisar o Código se reafirmou a necessidade de assegurar que as penas não sejam nocivas ao réu; no entanto, tal programa não foi traduzido em conteúdos concretos. Ao se optar por se prescindir das definições (para fixar-se somente em descrever os efeitos de cada pena) perdeu-se a ocasião de formular de modo mais adequado sua possível configuração como um projeto de bem, segundo emerge, não somente das mais convincentes reflexões da penalística moderna, mas também de um estudo mais atento dos fundamentos bíblicos, patrísticos e magisteriais em que se baseia a dimensão jurídica da Igreja.

É verdade que alguns efeitos de certas penas (por exemplo, a obrigação de residir em um território) e, sobretudo, as penitências (que no Código oriental estão incluídas entre as penas) consistem em comportamentos que nem sempre implicam privar ao destinatário de um bem ou um direito. Por essa razão, teria fundamento, não somente na tradição genuína, mas, também, na mesma lei, o esforço por estabelecer formulas técnicas que assegurem a natureza penal de medidas que sejam coerentes com os atos negativos realizados, expressando sua antítese positiva com obras modeladas, segundo os valores objetivos da concreta violação.

É curioso que no congresso ao qual aludi, o cardeal, como ocorre com quase todos os autores, não tenha feito qualquer menção à terceira finalidade das penas que indiretamente é apontada pelo cân. 1341, isto é, o restabelecimento da justiça. Este silêncio constituiria um novo grupo de aspectos problemáticos, pois sobre ele cabe se colocar mais de uma questão: tratar-se-ia de uma terceira função da pena, distinta da medicinal e da expiatória; incluiria a reparação do dano à vítima à qual, junto com a prevenção e a reparação do escândalo, se 
refere o cânon paralelo do Código oriental (cân. 1401), sem mencionar o restabelecimento da justiça; mais do que uma terceira finalidade seria um objetivo unitário ou comum das penas medicinais, das expiatórias e das demais sanções; e, sobretudo, como elemento primordial, qual justiça se buscaria restabelecer com a imposição das penas.

Deixei para o final este possível problema hermenêutico, porque a partir do meu ponto de vista, mais que um problema, o restabelecimento da justiça representa a solução das incertezas apontadas sobre os aspectos substanciais do direito penal vigente. Creio que assumir o restabelecimento da justiça como chave de leitura pode ajudar a evitar que a dificuldade de conjugar as distintas dimensões e sujeitos implicados na esfera penal termine por resultar paralisante. Para apoiar esta proposta cabe se referir, mais que às formas legais, à doutrina do magistério pontifício mais recente sobre o direito penal. Indico brevemente três discursos de três papas.

O primeiro é de Paulo VI em 1970 à Rota Romana, recordando que o poder coativo da Igreja tem sentido somente como serviço à integridade moral e espiritual da própria Igreja em sua totalidade, da qual faz parte o autor do delito, mesmo em caso de excomunhão. Coloco como exemplo a experiência da Igreja primitiva de cujo procedimento severo oferece testemunho São Paulo em sua Carta aos Coríntios. Trata-se, pois, de restabelecer aquela justiça na qual encontra fundamento a identidade da Igreja como comunidade salvífica, fórmula que, além dos objetivos da pena, pode orientar também seus conteúdos positivos. Restabelecer a justiça que fundamenta a identidade da Igreja equivale a compreender a pena como instrumento de comunhão, expressão utilizada por João Paulo II no discurso à Rota em 1979, para se referir às sanções como meios utilizáveis com o propósito de recuperar as carências de comunhão sobre o bem individual e comunitário que acarretam as condutas anti-eclesiais.

Para esclarecer dúvidas sobre a impossibilidade de interpretar o restabelecimento da justiça em chave de retribuição (que, mesmo minoritárias, não faltam entre certos canonistas) seria um bom recurso, além de relativamente recente, a mensagem de quaresma do ano de 2010 de Bento XVI (dezesseis). O papa menciona a definição de justiça de Ulpiano (dar a cada um o que é seu) para advertir que nela fica 
sem resolver o conteúdo do que seria "o que é seu" e que deveria ser assegurado a cada um e, além disso, com o risco de supor que o mal e a injustiça sejam realidades externas ao coração de todo ser humano, como se pudesse lutar contra isso intervindo-se desde fora, isto é, atuando em sentido negativo contra quem comete as violações. Ao referir-se a uma justiça superior o papa indica três chaves que me parecem úteis para a reflexão sobre o delito e sobre a reação penal diante do mesmo, como o restabelecimento da justiça.

Bento XVI (dezesseis) fala da justiça que deriva da lógica que confia no amor. Nessa chave cabe interpretar o delito, enquanto manifestação da injustiça, como uma ação que substitui a lógica que confia no amor do outro e para o outro, pela lógica da suspeição, da competição, do reter para si mesmo, e atuar somente por si mesmo. A pena não pode reproduzir essas mesmas lógicas, mas que tem que configurá-las a partir da antítese a essas perspectivas negativas.

Em segundo lugar, o papa se refere à justiça capaz de levantar o indigente; que vai além da justiça que procura a lei, pois Deus se antecipa em libertar o seu povo e somente depois entrega a lei, de onde se expressa o que Deus pretende como escuta de seu povo em termos de justiça nas relações humanas. Segundo essa referência poderia se entender o delito como fechamento à escuta e à relação com os demais provocada pela ilusão da autossuficiência; a intervenção penal deveria, pois, estruturar-se nas chaves que resultem mais úteis para desencadear o desejo de liberar o próprio coração, um objetivo que a lei por si só não pode conseguir.

Por último, o papa fala de justiça salvífica como gratuidade da expiação já conseguida por Cristo em seu sofrimento; não é uma expiação alcançada por sacrifícios humanos, pois sua atualização não pode consistir em utilizar meios cuja idoneidade se apoie no sofrimento que produz, mas, sim, na capacidade de suscitar a descoberta da indigência para os outros, a necessidade de obter seu perdão e amizade, através de gestos positivos de amor.

Sou consciente que estas chamadas profundas para interpretar a finalidade das penas em chave unitária do restabelecimento da justiça salvífica que dá fundamento à identidade da Igreja pode suscitar ceticismo, especialmente em quem considera que não é competência do 
direito, e menos ainda, do direito penal, metas tão altas como aquelas indicadas. Quem assim pensa considera que ao direito penal corresponde somente restabelecer a justiça legal, que se consegue na medida em que se logre prever no ordenamento legal uma reação em si mesma reparadora da injustiça que comporta o delito. Assim, ao direito penal não incumbiria, por exemplo, que o autor da violação se emende de fato, mas somente assegurar, prevendo sanções adequadas, o restabelecimento da ordem justa; a efetiva correção do réu tornaria somente mais perfeito esse restabelecimento, já em si suficiente com a previsão de penas.

\section{As condições para aplicar no âmbito canônico os ideais da justi- ça reparativa}

Diante dessa séria dificuldade creio que não possa cair no esquecimento as constantes chamadas de atenção do magistério sobre a necessidade de evitar diferenças entre a justiça real e a justiça legal. Trata-se de uma advertência dirigida geralmente aos processos de nulidade matrimonial. Porém, não creio que deixe de ter incidência no sistema penal, sem que esse esforço por unir justiça legal e real obrigue a abandonar a técnica penalística ou empurre para cair nos braços de confusas e mal-entendidas abordagens pastorais.

Creio que um válido suporte técnico com o objetivo de alcançar uma justiça penal integral, e não somente legal, provém dos princípios e conceitos da justiça reparativa. No entanto, é preciso reconhecer, sem meios termos, que sua aplicação no sistema penal canônico requer que sejam asseguradas algumas condições que possam suprir as lacunas que, ao menos em sua interpretação e aplicação prática, destacamos anteriormente. Indico agora três dessas instâncias ou condições, com suas relativas repercussões formais ou técnicas.

A primeira, podemos formulá-la como necessidade de fazer um maior esforço no âmbito da prevenção primária que se refere ao compromisso cultural do ordenamento por salvar a credibilidade intrínseca dos valores tutelados penalmente.

Neste terreno, em que pode unicamente se fundamentar aquela prevenção que nasce do livre convencimento, e que está estritamente 
relacionada com os conceitos técnicos da tutela antecipada dos bens, da atenção à situações de risco delituoso e de possíveis perfis de corresponsabilidade de ofícios ou instituições aos quais corresponde velar pela legalidade, temos de reconhecer com humildade as deficiências do sistema canônico, ao menos no chamado "direito vivente". Não entro no que, se for dado, resultaria ser de longe a maior deficiência e a que acarretaria o pior descrédito do sistema penal, isto é, por qualquer que fosse a razão (permissividade excessiva, inércia ou, pior, por motivos menos inocentes) os fiéis percebessem vantagens na situação eclesial de quem (pessoas físicas, jurídicas, grupos ou associações, etc.) costuma se colocar à margem ou em contraste com a lógica de comunhão e serviço, na qual se fundamenta a legalidade e disciplina canônica. Todos nós esperamos e todos nós rezamos para que o Senhor afaste de sua Igreja perigo semelhante, que seria muito grave.

Embora sem chegar a tanto, creio que há três âmbitos que devem ser melhorados para que o esforço de prevenção primária seja eficaz. Neles o papel das autoridades da Igreja particular é central, conforme a eclesiologia conciliar. O primeiro âmbito é a atenção que podem requerer certas matérias que, embora estejam reguladas fora do direito penal, devem ser mais bem protegidas para se evitar situações desconcertantes na atividade pastoral e entre os fiéis, semeando dúvidas sobre se certos valores são ou não imprescindíveis para a identidade da Igreja, de seus ensinamentos e de sua missão. Tal proteção pode sugerir, pelas circunstâncias do lugar, traduzir em lei penal canônica alguns delitos estatais, como pertencer ao crime organizado ou à exaltação do terrorismo, mesmo sem ter cometido diretamente homicídios, mutilações ou raptos (únicos pressupostos penais); às vezes, aqueles que atuam dessa forma professam-se católicos e fazem ostentação disso, como mostram alguns casos conhecidos da criminalidade organizada na Itália.

Há outros casos relacionados com a disciplina eclesiástica que não requerem maior penalização pela via legislativa, mas, sim, que se tomem medidas para assegurar sua observância. Entre essas são dignas de menção as normas sobre formação e preparação para o ministério ordenado; as que regulam o desenvolvimento corresponsável das principais funções e serviços na comunidade; e, de maneira especial, 
as normas sobre o exercício colegial e pessoal dos ofícios de governo, único setor em que se preveem delitos culposos. Tal previsão não significa que, em caso de negligência no governo, o único elemento relevante seja o delito, isto é, causar um dano efetivo, como se no governo não tivesse relevância em si mesmo a observância diligente das normas, seja das que se referem à conduta pessoal do titular (como a dedicação do ofício), seja das que se referem à relação do titular com outros sujeitos (como as que estabelecem consultas ou prestação de contas em uma gestão).

O segundo âmbito digno de melhora para uma prevenção primária mais eficaz é o equilíbrio entre a moderação no legislar e a intervenção em tempo e pontual em certas situações de risco. Talvez entre a moderação tão necessária no pós-concílio e algumas circunstâncias sucessivas tenha se dado uma mudança de sensibilidade que exige atuar com equilíbrio para não se ter que tardiamente lançar mão da norma excepcional conclusiva do direito penal, com o risco de irrogar sanções com o único objetivo de fortalecer a ação de governo e defender a instituição a custa da garantia das pessoas, buscando iludir dessa forma possíveis corresponsabilidades.

Na Igreja não existe reserva de lei, razão pela qual é preferível recorrer a tempo ao preceito penal, que é um meio eficaz contra os riscos que podem conter certas condutas limites na falta de observância da disciplina sobre o culto e a administração de bens; ou fundadas em um personalismo indevido na pastoral e no governo, ou em imprudências não suficientemente discernidas em espírito de comunhão e de serviço. Os preceitos exigem diálogo com quem, pelo conteúdo do mesmo, pode se ver atacado em seus direitos, seja quando chega a constituir um delito não diretamente previsto. Tal diálogo deveria resolver o risco de que, atrás do preceito, esconde-se somente uma coação autoritária e não a proteção de um bem eclesial necessário.

Nesse sentido, é preciso melhorar, a partir da autenticidade e da transparência, os canais de comunicação entre o fiel implicado nas condutas arriscadas e a autoridade à qual corresponde emanar o preceito. Essa é a terceira dimensão em uma prevenção primária eficaz. Tal exigência recai sobre as medidas prévias, remédios penais ou pastorais, de forma que sejam entendidos como atos jurídicos em sentido 
estrito, portanto, realizados na forma escrita que caracteriza habitualmente os atos de governo, com sucessivo deposito de uma cópia no arquivo oportuno, e com notificação formal ao fiel interessado. A essas garantias da comunicação antes de emanar o preceito, se acrescenta, ainda a motivação do preceito que deve se fazer constar ao menos sumariamente.

A segunda instância ou condição necessária para aproveitar o suporte técnico que a teoria da justiça reparativa oferece para o direito penal substancial é uma maior atenção à vitimologia. Geralmente se entende tal atenção em relação à reparação do dano provado à pessoa física vítima de um delito e à sua possível participação no processo penal. Trata-se de uma exigência atualmente por demais sentidas, nos delitos que tem como vítima uma pessoa física; porém, além das contingências do momento, não seria aceitável que as necessidades de quem sofreu as consequências do delito não ocupassem o posto principal, pois a Igreja tem a missão de anunciar a justiça salvífica, não de qualquer maneira, mas a partir da opção por quem sofre a injustiça. É uma condição indispensável para que haja coerência entre ortodoxia e ortopráxis.

Para além das consequências processuais, creio que na consciência eclesial estão muito presentes os desafios que na penalística moderna se unem à vitimologia, entre os quais cabe destacar o fato de que o autor do delito seja considerado vítima do mesmo (às vezes, não somente por tê-lo cometido, mas por ter sofrido algo semelhante anteriormente); que também a comunidade eclesial enquanto tal, e não somente seus responsáveis, seja tratada como vítima final (em alguns delitos a comunidade é a única vítima); que o delito suscite a saudável autocrítica sobre a autenticidade no modo de viver e evangelizar; que não se deixe de anunciar às vítimas dos delitos a esperança no evangelho, que se fundamenta no anúncio da verdade, mas que esta verdade não impeça o perdão e a reconciliação; e, por fim, que a pertença do autor do delito à comunidade seja motivo para que toda a comunidade assuma obrigações de reparação às vítimas. Na carta do papa aos fiéis da Irlanda se enumeram todos esses aspectos.

No horizonte do restabelecimento da justiça, a vitimologia exigiria buscar canais para uma adequada presença da vítima do delito na- 
queles aspectos ligados a recuperação do réu. Quero dizer que as exigências da vítima, quer seja a comunidade, quer seja uma pessoa física, são uma boa referência para não se marginalizar a orientação conciliativa, evitando que a pena acabe sendo nociva para o réu. Todavia é preciso evitar que o discernimento sobre sua recuperação se realize em chaves individualistas, sem submeter a autenticidade de sua visão pessoal sobre a própria vocação e papel na Igreja a crítica. Não é fácil encontrar caminhos para tornar realidade estas exigências. A ação do promotor de justiça encarna de forma limitada a presença da comunidade como vítima e suas relativas exigências na recuperação do réu; quando as vítimas são pessoas físicas é importante que alguém assuma o papel de representar suas instâncias. Trata-se, porém, de um terreno escorregadio no qual se deve evitar lógicas de vingança, como às vezes ocorre fora do âmbito canônico com algumas associações de vítimas; não é fácil estabelecer tal representação em uma lógica de conciliação; nisso consiste parte de meu papel como advogado nos casos de alguns delitos reservados à Congregação para a Doutrina da Fé.

Com isso chegamos à última das instâncias à qual pode contribuir, sem prejudicar o seu caráter técnico, o ideal da justiça penal reparativa; trata-se da personalização da pena como um projeto de bem em seus próprios conteúdos, e não só naquilo que são os seus objetivos teóricos. Reagir diante do delito em termos positivos e de responsabilização, capazes de reparar as exigências das vítimas, é a melhor síntese dos ideais da justiça reparativa e um dos melhores testemunhos que, como cultura jurídica, hoje pode oferecer o sistema canônico que, na esfera penal, funde suas raízes no valor da penitência, uma medida canônica tradicionalmente estruturada a partir das obras concretas e não somente a partir da privação de bens.

\section{Conclusão}

Nas circunstâncias atuais, vista a complexidade do instituto da penitência (cujo ordenamento atribui também a função de um maior agravo da própria pena), o passo corajoso e profético poderia ser constituído por uma expressa previsão na lei penal desta alternativa, indicando, além disso, que toda sanção integra conteúdos que expressam 
comportamentos opostos àqueles assumidos quando se cometeu o delito. Bastaria acrescentar uma norma que desenvolvesse tal alternativa em sua duração e nos sujeitos que devem acompanhar o réu, ainda que em relação aos conteúdos seja melhor se ater às fórmulas gerais que permitam adaptá-las à cada caso, segundo a personalidade do autor do delito, a repercussão comunitária de sua ação e a incidência de várias instâncias de possíveis pessoas físicas prejudicadas pelo delito.

\section{BIBLIOGRAFIA}

D. Pulitanò, Qaule futuro per la giustizia minorile, en MinoriGiustizia 1-2-, 2002, pp. 81 ss.

E. M. Egan, I processi speciali, en AA.VV., Il nuovo codice di diritto canonico. Novità, motivazione e significato, Roma, 1983, 499.

F. Scaparro, Il coraggio di mediare. Contesti, teorie e pratiche di risoluzioni alternative delle controversie, Milano, 2001.

G. Di Mattia, Il diritto penale a misura d'uomo, en Apolinnaris 64, 1991, pp. 747-770.

G. Mannozzi, La giustizia senza spada, Milano, 2003.

G. Puntillo, Decreto penale extragiudiziale canonico e diritto di difesa, Città del Vaticano, 2010.

L. Eusebi, Profili della finalità conciliativa nel diritto penale, en AA. VV., Studi in onore di G. Marinucci. Teoria della pena e teoria del reato, II, Milano 2006, pp. 1109-1127.

L. Eusebi, Responsabilità morale e giuridica del gobernó ecclesiale. Il ruolo dei vescovi in rapporto ai fatti illeciti dei chierici nel diritto canonico e nel diritto italiano, en P. Gherri (ed.), Responsabilità ecclesiale, corresponsabilità e rappresentanza, Città del Vaticano, 20010, pp. 83-104.

L. Eusebi, Riparazione e riconciliazione nel diritto penale, en Archivio Giuridico 137, 2006, pp. 269-301.

L. Eusebi, Ripensare la modalità della risposta ai reati, en Cassazione Penale 49, 2009, 4938-4958. 
M. J. Arroba Conde, Convincimento, certezza e motivazione: l'esperienza canonica, en Criminalia, 2013, pp. 163-180.

M. J. Arroba Conde, Diritto processuale canonico ( $6^{\text {a }}$ edición), Roma, 2012.

M. J. Arroba Conde, Relación entre las pruebas y la comprobación de la verdad en el proceso canónico, en Anuario de derecho canónico 1, 2012, pp. 11-36.

M. L. Hadley, Th spiritual roots of restorative justice, New York, 2001.

M. Riondino, Connessione tra pena canonica e pena statuale, en AA. VV., Questioni attuali di diritto penale canonico, Città del Vaticano, 2012, pp. 199-225.

M. Riondino, Giustizia riparativa e mediazione nel diritto penale canonico ( $2^{\circ}$. Ed.).

Roma, 2012.

M. Riondino, Il minore di fronte alla giustizia, en Commentarium pro Religiosis 87, 2006, pp. 149-170;

M. Riondino, Justicia restaurativa y mediación juvenil. La experiencia en Italia, en Ministero della Giustizia (ed.), Nuove esperienze di giustizia minorile, Roma, 2009, pp. 27-40.

P. Ronzani, La pena ecclesiale, Padova, 2004.

Signatura Apostolica, coram Ratzinger, sentencia Romana, 27.10.1984, Dimissionis a munere docendi, en Il diritto eclesiástico 96, 1985, pp. 260-270.

Z. Grocholewski, Presentazione, en Z. Suchecki, Il processo penale canonico, Città del Vaticano, 2003, pp. 5-9. 